\title{
Formulation Development, in Vitro Evaluation and Stability Study of Aceclofenac Tablet
}

\author{
Ozgul Gungor Culcu ${ }^{*}$ and Inci Arisan \\ Department of Chemistry, Yıldız Technical University, Istanbul 34220, Turkey
}

\begin{abstract}
The objective of the study was to develop film coated tablets of aceclofenac using wet granulation technique. Possible drug-excipient interaction was evaluated by HPLC (high performance liquid chromatography) and FTIR (fourier infrared spectroscopy). The tablets prepared were assessed for their physicochemical, in vitro dissolution at $\mathrm{pH} 1.2,4.5,6.8$ and 7.5 and stability characteristics. Comparison with a commercial aceclofenac product was made in vitro and in vitro studies. There was no interaction between aceclofenac and used excipients. Furthermore, the physicochemical properties of the tablets were satisfactory. The dissolution profile of one of the formulated aceclofenac tablets (D07) was statistically similar $(p<0.05)$ to that of the commercial aceclofenac brand in all the dissolution media. The formulated products ware stable and showed no changes in physical appearance, drug content, or dissolution pattern after storage at $40{ }^{\circ} \mathrm{C} / 75 \% \mathrm{RH}$ for 6 months. The results indicate that it is feasible to achieve a stable aceclofenac tablet formulation by using wet granulation technique.
\end{abstract}

Key words: Aceclofenac, film coated tablets, dissolution profiles, stability studies.

\section{Introduction}

The main purpose of solid dosage form is to make a drug available to the human body at a certain rate and define amount through the gastro intestinal tract so that the drug can produce pharmacological effects. But studies on bioavailability of drugs from a given dosage form revealed that, in many situations, solid dosage forms did not give the same therapeutic effects [1-3]. Aceclofenac FDA (US food and drug administration) from class 2 groups according to BCS (biopharmaceutics classification system) classification weak acid is a substance made. Rapidly absorbed after oral administration and the absolute bioavailability of approximately $100 \%$. Formulation development of aceclofenac used, freely soluble in acetone, 96\% ethanol-soluble, practically insoluble in water. Aceclofenac has an active lipophilic and practically insoluble in water.

NSAIDs (non-steroidal anti-inflammatory drugs) are considered to be the first-line drugs in the

\footnotetext{
*Corresponding author: Ozgul Gungor Culcu, Ph.D., research field: biochemistry. E-mail: ogungor08@gmail.com.
}

symptomatic treatment of rheumatoid arthritis, osteoarthritis and ankyliosis spondylitis [4-6]. Aceclofenac is one of the emerging NSAID molecules for arthritis treatment. It is a newer derivative of diclofenac and has less gastrointestinal complications. The successful treatment of arthritis depends on the maintenance of effective drug concentration level in the body for which a constant and uniform supply of drug is desired. Aceclofenac is a newer derivative of the diclofenac group of NSAID that exhibits analgesic and anti-inflammatory activities. It directly blocks the prostaglandin synthesis and has less gastrointestinal complications [7-9]. It is a recommended first-line drug in the symptomatic treatment of rheumatoid arthritis, Osteoarthritis and ankylosing spondylitis. Aceclofenac, i.e., 2-\{2-\{2-(2,6 dichlorophenyl)amino $\}$ phenyl acetyl oxy acetic acid, has a short biological half life of approx $4 \mathrm{~h}$ and a dosing frequency of 200 mg daily in two divided doses [10-12].

Aceclofenac is a phenyl acetic acid and the chemical structure is shown in Fig. 1 [13]. The solubility of Aceclofenac, a weakly acidic drug ( $\mathrm{pKa}$ 4-5), depends on pH. AC is highly soluble in basic 
conditions but relatively soluble in water and acidic $\mathrm{pH}$ conditions. It exhibits poor flow and compression characteristics [14-16]. Several methods are available in literature to determine the concentration of AC. Techniques used for analysis of $\mathrm{AC}$ include titrimetric, voltammetric, densitometric, colorimetric, spectrophotometric, spectroflourometric, polarographic, HPLC (high performance liquid chromatography), capillary electrophoresis, and mass spectrometry. Different analytical methods have been developed for the simultaneous determination of AC combinations with various active molecules. Throughout the stability test, AC in plasma has proved stable at room temperature for at least $6 \mathrm{~h}$ [17].

\section{Experiments}

\subsection{Materials}

Aceclofenac (Suyash Laboratories Limited), Microcrystalline cellulose (JRS Pharma), Croscarmellose sodium (Vivasol) (JRS Pharma), Povidon K-30 (BASF), Glyceryl distearate (Type I) (Gattefosse), Ethanol (JT Baker), Advantia Prime (ISP) has been supplied. All other chemicals used were of pharmaceutical grade.

\subsection{Methods}

All excipients are tested on conformance to description and identification with an accompanying supplier's certificate of analysis. The analytical methods used to test the excipients are those described in the European Pharmacopoeia.

\subsection{Assay of Aceclofenac Quantitative Determination of Aceclofenac}

It was performed by HPLC. A gradient HPLC (Shimadzu Corporation, Kyoto, Japan) UV/VIS Detector Hichrom Kromosil100 5 C18 250 mm $\times 4.6$ mm, $5 \mu$ column was used. The mobile phase used was a mixture of Mobile Phase A/Mobile Phase B in a ratio of 3:2. The filtered from $0.45 \mu \mathrm{m}$ mobile phase was pumped at a flow rate of $1.0 \mathrm{~mL} / \mathrm{min}$ and the column temperature was maintained at $25{ }^{\circ} \mathrm{C}$. The eluent was detected by a UV detector at $275 \mathrm{~nm}$.

\subsection{Dissolution Method}

The solubility of Aceclofenac significantly increases with the $\mathrm{pH}$ of media. As the result of dissolution study $\mathrm{pH} 6.8$ phosphate buffer media and the Pallet method have been selected. UV-Vis On-line Dissolution System was used in $75 \mathrm{rpm}$ speed by a UV detector at $275 \mathrm{~nm}$.

\subsection{Preparation of Aceclofenac Tablet}

The tablets were prepared by a wet granulation

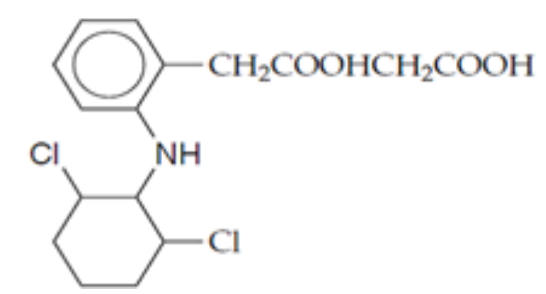

Fig. 1 Chemical structure of aceclofenac.

Table 1 Composition of formulation trials.

\begin{tabular}{lllllll}
\hline \multirow{2}{*}{ Ingredients } & \multicolumn{7}{c}{ Using rate (\%) } \\
\cline { 2 - 7 } & D 02 & D 03 & D 04 & D 05 & D 06 & D 07 \\
\hline Aceclofenac & 47.6 & 47.6 & 47.6 & 47.6 & 47.6 & 47.6 \\
Microcrystalline cellulose (PH 101) & 43.4 & 43.4 & 42.4 & 40.4 & 30.4 & 30.4 \\
Crosscarmellose sodium & 3.0 & 2.0 & 4.0 & 6.0 & 6.0 & 6.0 \\
Povidon K-30 & 3.0 & 5.0 & 4.0 & 4.0 & 4.0 & 4.0 \\
Microcrystalline cellulose (PH 102) & 3.0 & 2.0 & 2.0 & - & 10.0 & 10.0 \\
Glyceryl distearate (Type I) & 37.0 & 37.0 & 37.0 & 2.0 & 2.0 & 2.0 \\
Purified water* & 47.6 & 47.6 & 47.6 & 37.0 & 37.0 & - \\
Ethanol* & - & - & - & - & - & 22.2 \\
\hline
\end{tabular}

* Prepared according to the total powder are given as weight/weight. Granulation solvent is not included in the finished product. 
technique. The composition of the tablet formulations are given in Table 2. 1/3 of Aceclofenac, microcrystalline sodium and crosscarmellose sodium were mixed in granulator for $5 \mathrm{~min}$. The blend was granulated with the aid of PVP K-30 and ethanol/water.

The mass dried in a hot air oven at $40{ }^{\circ} \mathrm{C}$ until moisture is not more than $3.0 \%$. The dried granules were sieved through a $600 \mu \mathrm{m}$ sieve. $2 / 3$ of crosscarmellose sodium was added to sieved granules and mixed in $15 \mathrm{rpm}$ for $15 \mathrm{~min}$. Glyceryl distearate was sieved through a $300 \mu \mathrm{m}$ sieve and added to the blend and mixed in $15 \mathrm{rpm}$ for $3 \mathrm{~min}$. Prepared granules of Aceclofenac $100 \mathrm{mg}$ were compressed as $210.0 \mathrm{mg} \pm 10 \%$.

\subsection{Physiochemical Characterization of the Tablets}

Tablet weight variation was evaluated using 10 tablets with an electronic balance while tablet hardness and friability were determined for 10 tablets electronic friabilator for $4 \mathrm{~min}$ at $25 \mathrm{rpm}$, respectively.

\subsection{In Vitro Evaluation}

In vitro dissolution test was carried out in $900 \mathrm{~mL}$ of simulated pH 6.8 phosphate buffer. The dissolution medium was kept in thermostatically controlled water bath, maintained at $37 \pm 0.5{ }^{\circ} \mathrm{C}$. The pre-weighed tablet was then introduced into the dissolution jar and the palette was rotated at $75 \mathrm{rpm}$. It was analyzed spectrophotometrically at $275 \mathrm{~nm}$.

\subsection{Stability Studies}

Stability studies were conducted on a strip pack of one of the aceclofenac test formulation (D07) in order to assess its stability after storage at $40{ }^{\circ} \mathrm{C} / 75 \% \mathrm{RH}$ for 6 months. Samples were withdrawn at 1, 3 and 6 months and evaluated for the analysis results.

\section{Results}

\subsection{Studies on API (Aceclofenac Active Pharmaceutical} Ingredient)

The solubility of aceclofenac $(\mathrm{mg} / \mathrm{mL})$ was as follows: $0.1 \mathrm{M} \mathrm{HCl}(\mathrm{pH} 1.2), 0.027 \pm 0.010$; $\mathrm{pH} 4.5$ acetate buffer, $0.199 \pm 0.010 ; \mathrm{pH} 6.8$ phosphate buffer $5.628 \pm 0.010$.

Figs. 2 and 3 show the spectra of the pure drug and

Table 2 Solubility of Aceclofenac.

\begin{tabular}{lll}
\hline Media & Solubility $(\mathbf{m g} / \mathbf{m L})$ & Dose/solubility \\
\hline pH 1.2 & 0.027 & $3,700 \mathrm{~mL}$ \\
pH 4.5 & 0.199 & $502 \mathrm{~mL}$ \\
pH 6.8 & 5.628 & $17.8 \mathrm{~mL}$ \\
\hline
\end{tabular}

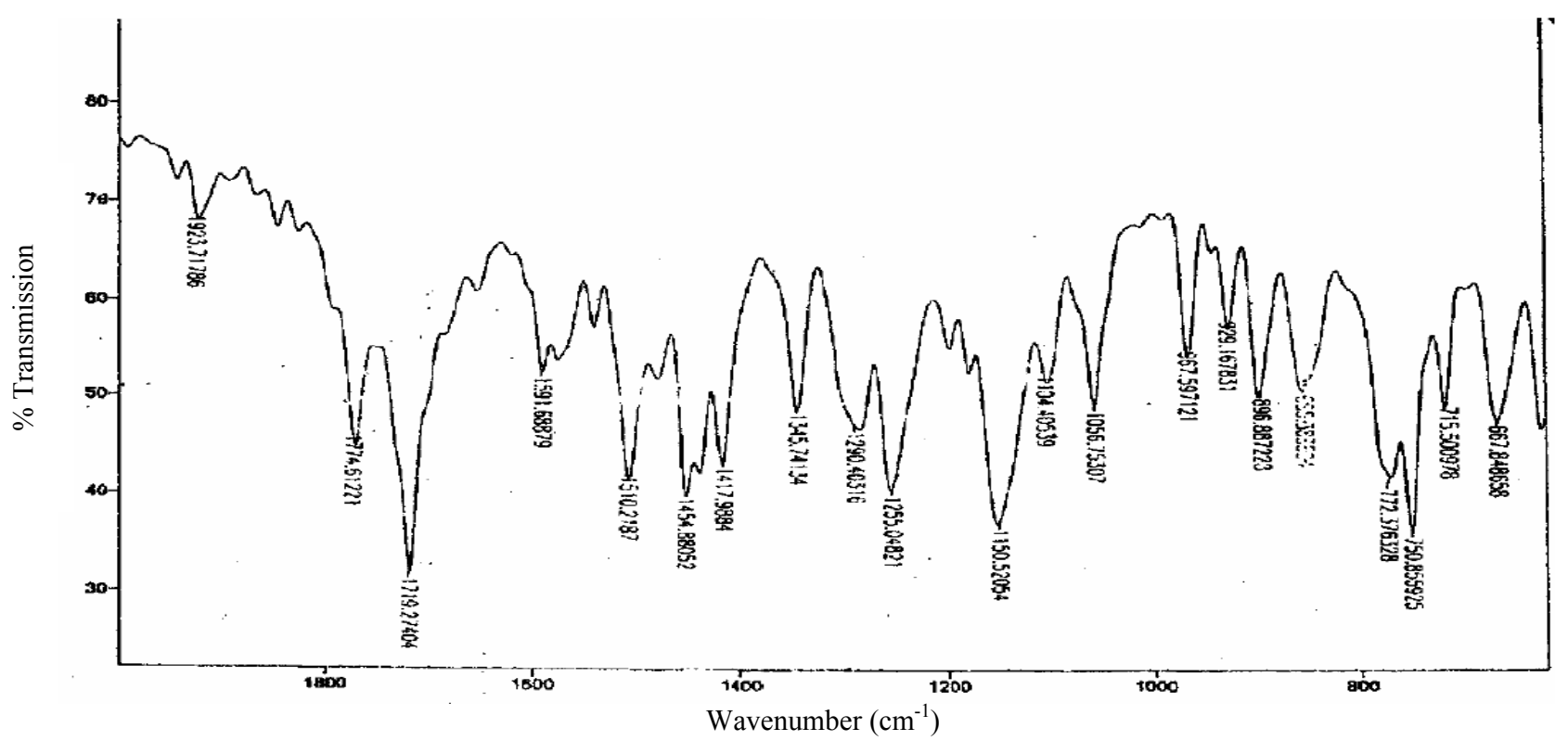

Fig. 2 FTIR spectrum of pure aceclofenac. 


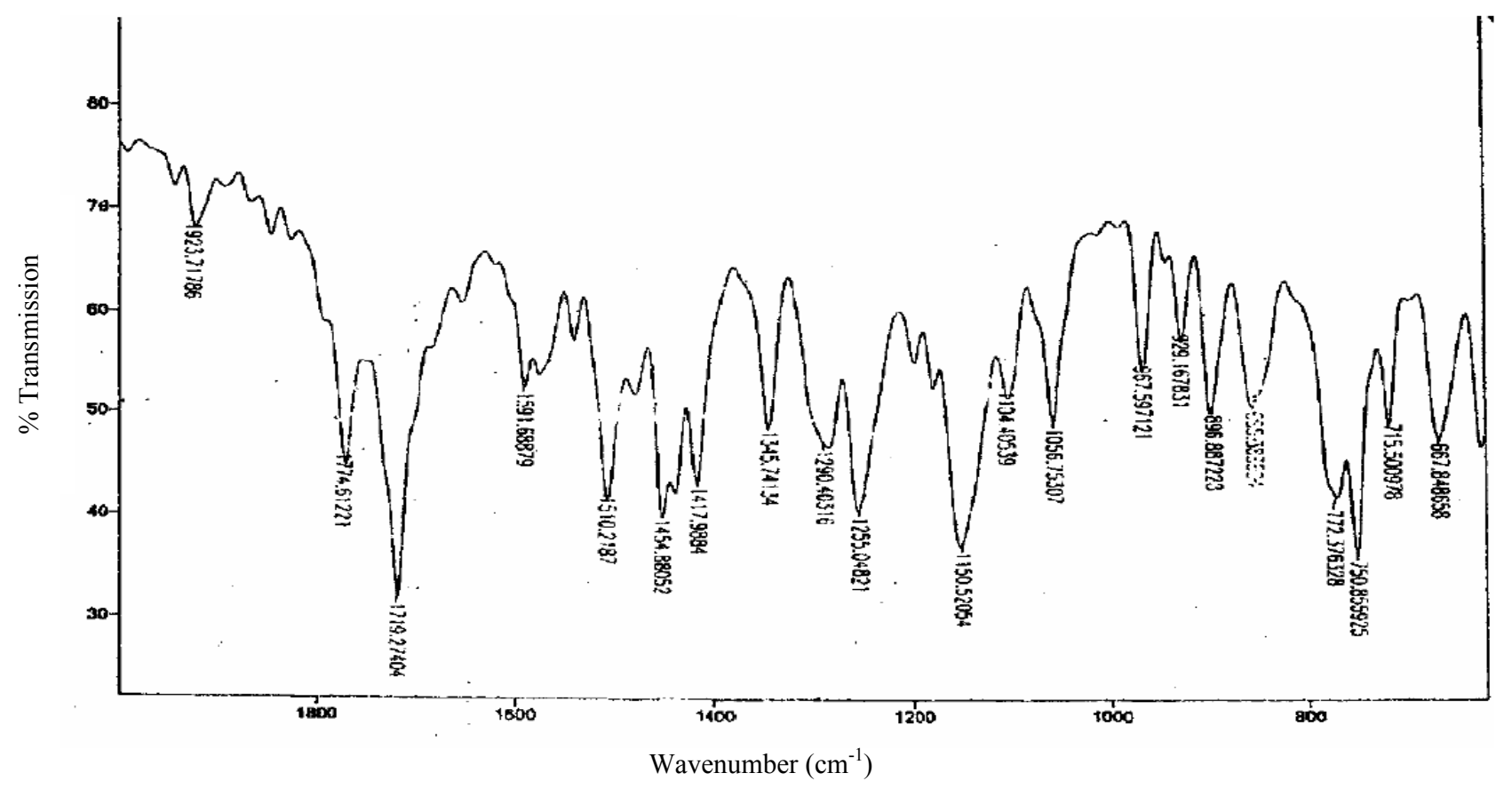

Fig. 3 FTIR spectrum of aceclofenac tablet.

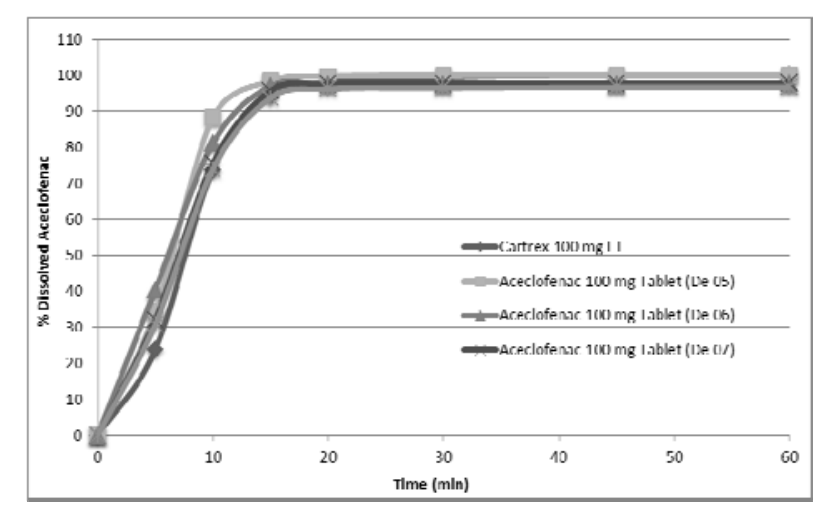

Fig. 4 Comparative dissolution profile of aceclofenac tablet trials in pH 6.

tablet formulation (D07), respectively. The spectrum for pure aceclofenac showed major peaks. Formulation D07 spectrum also showed similar peaks at the above wave numbers.

\subsection{Calculation of Similarity Factor}

The similarity factor (f2) was also calculated using below Eq. (1).

$$
\mathrm{f} 2=50 \log \left\{\left[1+1 / \mathrm{n} \sum \mathrm{n}_{\mathrm{t}=1}\left(\mathrm{R}_{\mathrm{t}}-\mathrm{T}_{\mathrm{t}}\right)^{2}\right]^{-0.5} \times 100\right\}
$$

where, $n=$ no. of full points, $R t=$ the reference profile at the time point, $t$, and $T t=$ the test profile at the same point.

The similarity factor (f2), when the drug release data for D07 and the reference product were compared in various dissolution media were as follows: $\mathrm{pH} 1.2$, $\mathrm{f} 2=76.4, \mathrm{pH} 4.5, \mathrm{f} 2=79.5, \mathrm{pH} 6.8, \mathrm{f} 2=72.2 . \mathrm{f} 2$ value between 50 and 100 suggest that two dissolution profiles are similar. Drug release from D07 in pH 6.8 media was similar to that of the reference tablet thus indicating that both formulations behaved in a similar manner in this dissolution media.

\subsection{Physicochemical Properties of the Formulated Tablets}

Tablet thickness was in the range 3.6-3.9 mm; diameter, $11.0 \mathrm{~mm}$; and hardness, $10.0-14.0 \mathrm{~kg} / \mathrm{cm}^{2}$. Tablet friability and coefficient of weight variation of all the tablet batches were in the ranges 0.5 to $0.8 \%$ and 1.4 to $3.5 \%$, respectively. Drug content was satisfactory and uniform (>99\%) for all the batches of tablet formulations.

\subsection{In Vitro Drug Release}

The results of the in vitro drug release studies in simulated gastric and intestinal fluids are presented in Table 3. As shown in Table 3, drug release data for the reference tablets and test formulation D07 in 
Table 3 Comparative in vitro release profile of a test aceclofenac tablet formulation (D07) and reference product at pH 1.2, 4.5 and 6.8 .

\begin{tabular}{|c|c|c|c|c|c|c|c|}
\hline \multirow{2}{*}{ Product } & \multirow{2}{*}{ Dissolution medium } & \multicolumn{6}{|c|}{ Drug release $(\%)$} \\
\hline & & $5 \mathrm{~min}$ & $10 \mathrm{~min}$ & $15 \mathrm{~min}$ & $20 \mathrm{~min}$ & $30 \mathrm{~min}$ & $45 \mathrm{~min}$ \\
\hline D07 & \multirow{2}{*}{$\mathrm{pH} 1.2$} & $4.1 \pm 1.4$ & $14.7 \pm 1.4$ & $28.6 \pm 1.3$ & $39.3 \pm 1.1$ & $52.6 \pm 1.5$ & $64.6 \pm 2.0$ \\
\hline Reference & & $3.9 \pm 0.9$ & $14.3 \pm 4.4$ & $30.4 \pm 5.5$ & $42.7 \pm 4.6$ & $56.8 \pm 4.0$ & $68.3 \pm 3.7$ \\
\hline D07 & \multirow{2}{*}{$\mathrm{pH} 4.5$} & $10.7 \pm 1.6$ & $32.7 \pm 2.7$ & $50.2 \pm 2.2$ & $60.7 \pm 2.1$ & $73.3 \pm 2.3$ & $83.5 \pm 2.6$ \\
\hline Reference & & $11.8 \pm 1.9$ & $35.5 \pm 5.3$ & $53.3 \pm 3.9$ & $63.2 \pm 3.5$ & $74.2 \pm 4.1$ & $80.7 \pm 5.0$ \\
\hline D07 & \multirow{2}{*}{$\mathrm{pH} 6.8$} & $26.9 \pm 2.0$ & $66.1 \pm 2.2$ & $91.5 \pm 2.3$ & $96.6 \pm 1.7$ & $96.8 \pm 1.7$ & $96.8 \pm 1.7$ \\
\hline Reference & & $23.8 \pm 4.5$ & $73.6 \pm 9.1$ & $94.1 \pm 3.3$ & $98.1 \pm 3.2$ & $99.5 \pm 3.1$ & $99.9 \pm 3.1$ \\
\hline
\end{tabular}

Table 4 Stability results of a test Aceclofenac tablet formulation (D07) in accelerated condition.

\begin{tabular}{|c|c|c|c|c|c|}
\hline Shelf life Parameters & Limits & Initial & $1^{\text {st }}$ Month & $3^{\text {rd }}$ Month & $6^{\text {th }}$ Month \\
\hline Appearance & $\begin{array}{l}\text { White, round, biconvex, } \\
\text { coated tablets }\end{array}$ & Complies & Complies & Complies & Complies \\
\hline Weight & $(216.0 \mathrm{mg} \pm \% 7.5)$ & 214.6 & 215.9 & 216.6 & 218.2 \\
\hline Hardness & For information & $11.6 \mathrm{kp}$ & $14.2 \mathrm{kp}$ & $14.2 \mathrm{kp}$ & $15.8 \mathrm{kp}$ \\
\hline Moisture & NMT $4.0 \%$ & 1.9 & 2.1 & 2.6 & 2.5 \\
\hline Disintegration & $\begin{array}{l}\text { NMT. } 15 \mathrm{~min} / 37^{\circ} \mathrm{C} \\
\text { distilled water }\end{array}$ & 9 & 7 & 6 & 7 \\
\hline Assay & $(90.0 \mathrm{mg} / \mathrm{tb}-105.0 \mathrm{mg} / \mathrm{tb})$ & 98.3 & 96.3 & 98.0 & 95.5 \\
\hline Dissolution & NLT $85 \%$ in $30 \mathrm{~min}$. & 100.9 & 100.9 & 98.7 & 97.8 \\
\hline \multirow{2}{*}{$\begin{array}{l}\text { Related substances } \\
\text { Unknown unique Imp } \\
\text { Imp A Total Imp }\end{array}$} & $\begin{array}{l}\text { NMT } 0.2 \% \\
\text { NMT } 2.0 \%\end{array}$ & $\begin{array}{l}0.06 \text { (RRT:1.39) } \\
0.07\end{array}$ & $\begin{array}{l}0.06(\mathrm{RRT}: 2.2) \\
0.43\end{array}$ & $\begin{array}{l}0.16 \text { (RRT:2.25) } \\
1.4\end{array}$ & $\begin{array}{l}0.17 \text { (RRT:2.35) } \\
1.4\end{array}$ \\
\hline & NMT $3.0 \%$ & 0.15 & 0.59 & 1.7 & 1.7 \\
\hline
\end{tabular}

different $\mathrm{pH}$ media were similar, indicating both exhibited similar characteristics.

\subsection{Accelerated Stability Studies}

Appearance, weight, hardness, moisture, dissolution assay, dissolution and impurities values were determined to be within target limits of the shelf-life period. The results obtained from accelerated stability studies indicate that D07 tablets did not show any physical changes after 6 months. The results are presented in Table 4 . These data were not significantly different $(p<0.05)$. Furthermore, there was also no significant change $(p>0.05)$ in the drug release profile of the formulation over.

\section{Discussion}

The available literature on the solubility profile of aceclofenac indicates that the drug is freely soluble in acetone and practically insoluble in water. In the present study, aceclofenac showed $\mathrm{pH}$-dependent solubility; as $\mathrm{pH}$ was raised from 1.2 to 7.5 , solubility improved considerably.

There was no interaction between aceclofenac and the excipients used, thus indicating that the choice of excipients for the aceclofenac tablets was suitable. Furthermore, all the formulations showed satisfactory results in critical quality parameters.

\section{Conclusions}

All analytical and stability study results are supported that the quality parameters of developed formulation is significantly similar with the reference product and aceclofenac $100 \mathrm{mg}$ tablet is a stable, generic, pharmaceutical product. The formulation method employed is simple and should be adaptable for commercial scale up. 


\section{References}

[1] Islam, A., Islam, S., Shahriar, M., and Dewan, I. 2011. "Comparative in Vitro Dissolution Study of Aceclofenac Marketed Tablets in Two Different Dissolution Media by Validated Analytical Method." J Applied Pharm Science 01 (09): 87-92.

[2] Mutalik, A., Naha, A., Usha, N., Ranjith, A. K., Musmade, P., Manoj, K., et al. 2007. "Preparation, in Vitro, Preclinical and Clinical Evaluations of Once Daily Sustained Release Tablets of Aceclofenac." Arch Pharm Res. 30 (2): 222-234.

[3] Akkuş, A. Ş., and Tırnaksız, F. 2010. "A Nonsteroidal Antiinflammatory Drug: Aceclofenac.” Fabad J Pharm Sci. 35: 105-118.

[4] Chowdary, K. P. R., Enturi, V., and Reddy, C. A. "Formulation Development of Acecelofenac Tablets by Wet Granulation and Direct Compression Methods Employing Starch Citrate." Pharmacie Globale (IJCP) 2011, 7 (08), Hydrophobic Matrix Formers. AAPS Pharm Sci. Tech. 2006, 1: 1-9.

[5] Soni, T., and Chotai, N. 2010. "Assessment of Dissolution Profie of Marketed Aceclofenac Formulations.” J Young Pharm 2 (1): 21-26.

[6] Parfitt, K. 1999. "Analgesics, Anti-Inflammatory Andantipyretics." The Complete Drug Reference, 32nd ed., 2-12.

[7] Kay, A. E., Alldred, A., 2003. Rheumatoid Arthritis and Osteoarthritis. In: Walker R., Edwards C, (Eds) Clinical Pharmacy and Therapeutics, 3rd ed., London: Churchill Livingstone, 791-807.

[8] British Pharmacopoeia. 2005. The Stationary Office, MHRA, British Pharmacopoeial Commission Office, Vol 1, London.

[9] Mutalik, S., and Hiremath, D. 2000. "Formulation and
Evaluation of Chitosan Matrix Tablets of Nifedipine." The Eastern Pharmacist 10: 109-111.

[10] Reddy, R., Mutalik, S., and Reddy, M. S. 2003. “Once Daily Sustained Release Matrix Tablets of Nicorandil, Formulation and in Vitro Evaluation." AAPS. Pharm Sci. Tech. 61 (Supp4): 1-9.

[11] Kuksal. A., Tiwary, A. K., Jain, N. K., and Jain. S. 2006. "Formulation and in Vitro, in Vivo Evaluation of Extended Release Matrix Tablet of Zidovudine: Influence of Combination of Hydrophilic and Hydrophoble Matrix Formers.”AAPS Pharm Sci. Tech. 7 (1): E1-E9.

[12] Ghosh, S., and Barik, B. B. 2010. "Formulation and In Vitro Evaluation of Once Daily Sustained Release Formulation of Aceclofenac." Trop J Pharm Res. 9 (3): 265-273.

[13] Legrand, E. 2004. "Aceclofenac in the Management of Inflammatory Pain.” Drug Evaluation 5 (6): 1347-1357.

[14] Chub, L. 2009. A. Nonaqueous Liquid Parenteral Aceclofenac Formulation. US Patent 0,156,670, issued Jun 18, 2009.

[15] Zahradnik, H. P., Hanjalic-Beck A, and Groth K. 2010. "Nonsteroidal Anti-Inflammatory Drugs and Hormonal Contraceptives for Pain Relief from Dysmenorrhes: A Review." Contraception 81: 185-196.

[16] Usha, A. N., Mutalik, S., Reddy, M. S., Ranjith, A. K., Kushtagi, P., and Udupa, N. 2008. "Preparation and in Vitro Preclinical and Clinical Studies of Aceclofenac Spherical Agglomerates." Eur J Pharm Biopharm 70: 674-683.

[17] Gowda, K. V., Rajan, D. S., Mandal, U., Selvan, P. S., Sam Solomon, W. D, Bose, A., et al. 2006. "Evaluation of Bioequivalence of Two Formulations Containing 100 Milligrams of Aceclofenac." Drug Dev Ind Pharm 32: 1219-1225. 